\title{
Vitamin K Intake, Body Mass Index and Warfarin Maintenance Dose
}

\author{
Edmond K. Kabagambe ${ }^{a} \quad$ T. Mark Beasley ${ }^{b}$ Nita A. Limdi ${ }^{c}$ \\ a'Division of Epidemiology, Department of Medicine, Vanderbilt University Medical Center, Nashville, Tenn., and \\ Departments of ${ }^{\mathrm{b}}$ Biostatistics and ${ }^{\mathrm{C}}$ Neurology, University of Alabama at Birmingham, Birmingham, Ala., USA
}

\section{Key Words}

Warfarin · Vitamin K · Obesity · Body mass index

\begin{abstract}
Background: Warfarin inhibits vitamin K-dependent coagulation factors. Being fat-soluble, the availability of vitamin $\mathrm{K}$ may vary according to body fat. We hypothesized that body mass index (BMI), a proxy of body fat, may interact with vitamin $\mathrm{K}$ intake in determining a warfarin maintenance (WM) dose. Methods: Patients with data on vitamin K intake, potential confounders and WM dose $(n=172)$ were included in linear regression models to test whether BMI modifies the relation between vitamin $\mathrm{K}$ intake and WM dose. Results: Warfarin loading dose correlated with the maintenance dose ( $r=0.36, p<0.0001)$ but was not significantly associated with WM dose in analyses adjusted for vitamin $\mathrm{K}$ epoxide reductase (VKORC1) and cytochrome P450 2C9 (CYP2C9) genotypes. In fully adjusted models, BMI was associated ( $\mathrm{p}=$ 0.001 ) with WM dose but vitamin $\mathrm{K}$ was only marginally positively associated $(p=0.06)$ with WM dose. We found no interaction ( $p>0.05$ ) between BMI and vitamin K intake with regard to WM dose. Inclusion of vitamin $\mathrm{K}$ intake in the model only slightly improved the amount of variance (1.1\%) explained by age, gender, BMI, race, physical activity, energy intake and VKORC1 and CYP2C9 genotypes. Conclusion: Our data suggest that body fat does not affect the relation between vitamin K intake and WM dose. (o) 2013 S. Karger AG, Basel
\end{abstract}

\section{KARGER}

E-Mail karger@karger.com

www.karger.com/crd

\section{Introduction}

Response to warfarin is highly variable within and across populations [1]. Both genetic and environmental variables such as diet and physical activity affect response to warfarin [2-4]. Although algorithms that incorporate genetic and environmental variables have been developed for clinical use in predicting response, a substantial amount of variation in warfarin response still remains unexplained $[2,4]$. Warfarin acts by inhibiting vitamin $\mathrm{K}$ epoxide reductase ( $V K O R C 1$ ), thereby inhibiting the vitamin K-dependent activation of coagulation factors (II, VII, IX and X). As vitamin $\mathrm{K}$ is fat-soluble, its amount and availability in tissues may vary according to body fat [5]. We hypothesized that obese individuals may have higher amounts of vitamin $\mathrm{K}$ in tissues and therefore require higher warfarin maintenance (WM) doses after adjusting for known determinants of warfarin response. Indeed, in patients treated with phenprocoumon, a coumarin derivative which inhibits vitamin $\mathrm{K}$ reductase, thereby blocking vitamin $\mathrm{K}$-dependent coagulation factors, the dose and time required to attain a desirable international normalized ratio (INR) is directly correlated with body mass index (BMI) in a dose-dependent manner [6]. Whether BMI modifies the relationship between vitamin $\mathrm{K}$ and warfarin response is not known.

As BMI [7] is strongly correlated with objective measures of fatness, e.g. dual energy X-ray absorptiometry 
(correlation coefficient range 0.55-0.96), BMI is a good proxy for body fat content. We investigated whether the relation between vitamin $\mathrm{K}$ intake and response to warfarin is modified by body fat at initiation of warfarin therapy. We also investigated whether inclusion of vitamin $\mathrm{K}$ intake in models improves the variance explained by established predictors of warfarin response.

\section{Methods}

\section{Study Population}

The Pharmacogenetic Optimization of Anticoagulation Therapy (POAT) and the Genetic and Environmental Determinants of Warfarin are ongoing prospective studies aimed at defining the influence of genetic polymorphisms on warfarin response [8]. $\mathrm{Pa}$ tients $\geq 20$ years of age were considered eligible if the intended duration of anticoagulation therapy was $\geq 2$ years. Therapy was managed at the anticoagulation clinic and the target INR range was $2-3$. The study was approved by the institutional review boards of the University of Alabama at Birmingham and the Jefferson County Health System. Participants gave written informed consent.

\section{Data Collection}

Detailed information including race, age, height, weight, indication for therapy, comorbid conditions and medications was collected as detailed elsewhere [8]. Factors influencing warfarin response, including warfarin loading dose, INR, concurrent medications and intake of alcohol and vitamin $\mathrm{K}$ were documented. Concurrent therapy with nonsteroidal anti-inflammatory drugs, antiplatelet agents or drugs that alter warfarin pharmacokinetics including cytochrome P450 2C9 (CYP2C9) inhibitors (e.g. amiodarone), CYP2C9 inducers (e.g. rifampin) or CYP2C9 substrates (e.g. losartan) were documented. In addition, we genotyped for variants in genes associated with warfarin dose [9], namely: VKORC1 [-1639G>A (rs9923231)], CYP2C9 [*2 (rs1799853), *3 (rs1057910), *5 (rs28371686), *6 (rs9332131), and *11 (rs28371685)] and CYP4F2 (rs2108622).

\section{Assessment of Vitamin K Intake}

Intake of vitamin $\mathrm{K}$ and other nutrients was estimated from three 24-hour dietary recalls (DR) using Nutrition Data System for Research (NDSR) ${ }^{\circledR}$ software [10]. We had previously showed that vitamin $\mathrm{K}$ intake assessed from $\mathrm{DR}$ was similar to that measured from the food frequency questionnaire [11]. Estimates of vitamin $\mathrm{K}$ intake from DR have been used in other studies and show positive correlation with warfarin dose required to attain INR [12]. Available DR were averaged to obtain a stable measure of vitamin $\mathrm{K}$ intake.

Out of 1,044 patients considered for inclusion in the current analysis, 578 were recruited as part of the POAT cohort which was established as part of a career-development award [8]. The funds in the POAT study were not sufficient to support a dietician for the assessment of vitamin $\mathrm{K}$ using 24-hour DR (NDSR). The cohort $(n=466)$ recruited through the GEDWR project provided the funds for the assessment of dietary vitamin $\mathrm{K}$ intake. At the time of the analyses for this study, 209 patients had completed the baseline dietary recalls.

\section{Statistical Analyses}

Warfarin loading dose was calculated as the total amount of warfarin a patient received divided by the total number of days taken before attaining target INR. Of the 209 patients, 11 were excluded for missing data on WM dose, VKORC1 or CYP2C9 genotypes and 23 for missing data on physical activity leaving 175 patients. In order to adjust for race in the models, the only patient of Asian descent was excluded from further analyses, leaving 108 white and 66 black patients. Two more patients with vitamin $\mathrm{K}$ intakes $(1,476$ and $1,513 \mu \mathrm{g} /$ day $)>4$ standard deviations above the mean were also excluded.

Vitamin $\mathrm{K}$ intake was adjusted for total energy intake using standard regression approaches $[11,13]$. The dependent variable, average WM dose, was square root-transformed to attain normality. Using ANOVA (SAS software version 9.2, Cary, N.C.), we tested whether vitamin $\mathrm{K}$ intake is associated with WM dose and whether this association is modified by BMI independent of VKORC1, CYP2C9, age, gender, physical activity and total energy intake. Additional analyses were performed adding variables such as race, education, income, $C Y P 4 F 2$ genotypes, alcohol use, smoking and warfarin loading dose, but none of these variables was significant in any of the models. In these analyses, both the main effects and interaction terms for energy-adjusted vitamin K and BMI were included.

To further investigate the effect of the interaction between BMI and vitamin $\mathrm{K}$ intake on warfarin response, we divided the study population into obese and nonobese individuals based on the standard definition for obesity, i.e. BMI $\geq 30 \mathrm{~kg} / \mathrm{m}^{2}$. The relation between vitamin $\mathrm{K}$ and WM dose was then examined after stratifying by obesity status.

Next we tested whether adding vitamin K to the model that includes standard predictors of WM dose improves the variance explained by the model. We used linear regression with square roottransformed WM dose as the dependent variable and energy-adjusted vitamin $\mathrm{K}$, total energy intake, age, gender, BMI, physical activity, VKORC1 and CYP2C9 genotypes as covariates. In this analysis, males were coded as 1 and females as $0, V K O R C 1$ genotypes were coded as 1 for ' $\mathrm{CT}$ ' and 'TT' and as 0 for ' $\mathrm{CC}$ ', while CYP2C9 was coded as 1 for the ' 11 ' genotype and 0 for all other genotypes ('12', '13', '22', '23', '33' and '111').

Results are reported as beta ( \pm standard error), standardized beta coefficients and adjusted $\mathrm{r}^{2}$. Variables in the model were considered significant at $\mathrm{p} \leq 0.05$.

\section{Results}

Of the 172 patients in the sample, $52 \%$ were female, $62 \%$ were white, $50 \%$ smoked cigarettes, $16 \%$ consumed alcohol, $63 \%$ had a college education or higher and $41 \%$ earned $\geq$ USD 50,000. Two percent of the patients were underweight (BMI $<18.5), 24 \%$ were of normal weight (BMI 18.5-24.9), 33\% were overweight (BMI 25-29.9) and $43 \%$ were obese $\left(B M I \geq 30 \mathrm{~kg} / \mathrm{m}^{2}\right)$. BMI ranged from 16.3 to 58.6 .

The median (25th, 75th percentile) vitamin $\mathrm{K}$ intake was $73.6 \mu \mathrm{g} /$ day $(45.9,168.0)$ and ranged from 11.7 to 714.7 
Table 1. Characteristics of the study population by quartiles of WM dose

\begin{tabular}{|c|c|c|c|c|c|}
\hline \multirow[t]{2}{*}{ Variable } & \multicolumn{4}{|c|}{ Quartiles of WM dose } & \multirow[t]{2}{*}{$\mathrm{p}$} \\
\hline & 1 (lower) & 2 & 3 & 4 (upper) & \\
\hline WM dose, $\mathrm{mg}$ & $2.91 \pm 0.84$ & $4.68 \pm 0.39$ & $6.10 \pm 0.49$ & $8.69 \pm 1.85$ & - \\
\hline Warfarin loading dose, $\mathrm{mg}$ & $5.42 \pm 1.19$ & $6.04 \pm 3.09$ & $6.94 \pm 4.20$ & $6.95 \pm 1.81$ & $<0.0001$ \\
\hline Vitamin $\mathrm{K}$ adjusted for energy, $\mu \mathrm{g} / \mathrm{day}$ & $121.39 \pm 125.47$ & $100.1 \pm 70.9$ & $96.3 \pm 71.3$ & $160.2 \pm 177.5$ & 0.68 \\
\hline Age, years & $65.4 \pm 14.3$ & $66.7 \pm 10.5$ & $59.8 \pm 11.9$ & $55.0 \pm 14.7$ & 0.003 \\
\hline $\mathrm{BMI}, \mathrm{kg} / \mathrm{m}^{2}$ & $29.1 \pm 8.5$ & $30.1 \pm 7.8$ & $30.6 \pm 6.4$ & $32.1 \pm 8.7$ & 0.20 \\
\hline Sex, \% women & 58 & 51 & 42 & 56 & 0.44 \\
\hline Race, $\%$ white & 74 & 70 & 65 & 40 & 0.04 \\
\hline Smoking, \% never-smokers & 49 & 54 & 49 & 49 & 0.96 \\
\hline VKOR, \% T-allele carrier & 70 & 65 & 37 & 14 & $<0.0001$ \\
\hline CYP2C9, \% with ' 11 ' genotype & 61 & 70 & 74 & 93 & 0.01 \\
\hline CYP4F2, \% G-allele carrier & 95 & 84 & 100 & 85 & 0.02 \\
\hline
\end{tabular}

Values are means \pm SD or $\%$.

$\mu \mathrm{g} /$ day. The mean warfarin loading dose was $6.3 \pm 2.9 \mathrm{mg}$ and ranged from 2.0 to $30.0 \mathrm{mg}$, while the average maintenance dose was $5.6 \pm 2.4 \mathrm{mg}$ and ranged from 0.92 to $15.6 \mathrm{mg}$. The average warfarin loading dose weakly correlated with the average maintenance dose in the study population as a whole (Spearman $\mathrm{r}=0.38, \mathrm{p}<0.0001$ ).

The characteristics of the study population by quartiles of WM dose are shown in table 1. Age, race, warfarin loading dose, VKORC1, CYP2C9 and CYP4F2 were all significantly associated $(\mathrm{p}<0.05)$ with WM dose in univariate analyses. Patients who required a higher maintenance dose tended to be younger, received a higher initial warfarin loading dose and were more likely to be black.

Surprisingly, BMI, smoking, income, education and current alcohol use were not significantly associated $(\mathrm{p}>$ 0.05 ) with WM dose (table 1). Although the association between BMI and the quartiles of WM dose was not statistically significant, there was a tendency for the maintenance dose to increase with increasing BMI. For instance, the mean BMI for the 1st, $2 \mathrm{nd}$, 3rd and 4 th quartiles of the WM dose was $29.1 \pm 8.5,30.1 \pm 7.8,30.6 \pm 6.4$ and $32.1 \pm$ 8.7 , respectively $(\mathrm{p}>0.05)$ (table 1$)$. The Spearman correlation between $\mathrm{BMI}$ and average warfarin loading dose was weak $(r=0.28, p=0.0003)$ but larger than the correlation between BMI and WM dose $(\mathrm{r}=0.19, \mathrm{p}=0.01)$.
Table 2 shows the relation between vitamin $\mathrm{K}$ intake and WM dose after adjustment for covariates. BMI was significantly associated $(\mathrm{p}=0.001)$, while vitamin $\mathrm{K}$ was marginally positively associated $(\mathrm{p}=0.06)$ with $\mathrm{WM}$ dose. There was no significant interaction between BMI and vitamin $\mathrm{K}(\mathrm{p}>0.05)$ before and after adjustment for covariates. Inclusion of vitamin $\mathrm{K}$ in the model improved the variance explained by $1.1 \%$ (table 2 ).

To further explore the potential interaction of vitamin $\mathrm{K}$ and BMI, we performed analyses stratified by obesity status and with WM dose as the dependent variable. There was no evidence for interaction in either group $(p>0.05)$.

\section{Discussion}

Contrary to our hypothesis, we did not observe a significant interaction between vitamin $\mathrm{K}$ intake and BMI with regard to WM dose. In accordance with the literature $[3,14]$, we confirmed statistically significant associations between WM dose and age, BMI, physical activity and $V K O R C 1$ and CYP2C9 genotypes. Unlike other studies that reported a small but significant association between CYP4F2 and warfarin dose [9], we only observed a weak association in univariate analysis, but not in analy- 
Table 2. Relation between vitamin $\mathrm{K}$ and WM dose

\begin{tabular}{|c|c|c|c|c|c|c|c|c|c|}
\hline \multirow[t]{2}{*}{ Variable } & \multicolumn{5}{|c|}{ Without vitamin $\mathrm{K}$ in the model } & \multicolumn{4}{|c|}{ With vitamin $\mathrm{K}$ in the model } \\
\hline & DF & beta & SE & $\mathrm{p}$ & STB & beta & SE & $\mathrm{p}$ & STB \\
\hline Age, years & 1 & -0.00967 & 0.00237 & $<0.0001$ & -0.26396 & -0.01050 & 0.00239 & $<0.0001$ & -0.28653 \\
\hline Gender, men vs. women & 1 & 0.05395 & 0.06648 & 0.4182 & 0.05400 & 0.05851 & 0.06598 & 0.3765 & 0.05855 \\
\hline BMI & 1 & 0.01353 & 0.00410 & 0.0012 & 0.21382 & 0.01391 & 0.00407 & 0.0008 & 0.21979 \\
\hline CYP2C9 & 1 & 0.24312 & 0.07631 & 0.0017 & 0.21245 & 0.24597 & 0.07570 & 0.0014 & 0.21494 \\
\hline Energy, kcal/day & 1 & 0.00002598 & 0.00005104 & 0.6114 & 0.03424 & 0.00002234 & 0.00005065 & 0.6598 & 0.02944 \\
\hline Vitamin $K, \mu \mathrm{g} /$ day & - & - & - & - & - & 0.00050834 & 0.00026368 & 0.0556 & 0.12324 \\
\hline Adjusted $r^{2}$ & & $33.2 \%$ & & & & $34.3 \%$ & & & \\
\hline
\end{tabular}

Values are from a linear regression model with the square root of average WM dose as the dependent variable and in which all the variables were modeled simultaneously. Age, BMI, vitamin K and total energy intake were modeled as continuous variables, while gender (black vs. white) and physical activity (active vs. sedentary) were modeled as dichotomous variables. CYP2C9 was coded as 0 if the genotype was ' 12 ', '13', '22', '23', '33', '111' and as 1 if the genotype was ' 11 '; VKOR was coded as 0 if the genotype was 'CC' and as 1 if the genotype was 'CT' or 'TT'. Variables such as race, smoking, income and education were excluded since they did not meet the 0.05 significance level to enter the model in the forward selection process. $\mathrm{DF}=$ Degrees of freedom; $\mathrm{SE}=$ standard error; $\mathrm{STB}=$ standardized beta . ses adjusted for CYP2C9. Furthermore, inclusion of vitamin $\mathrm{K}$ in a model with established predictors of warfarin response only slightly improved the variance explained by covariates (1.1\% improvement in model-adjusted $\left.\mathrm{r}^{2}\right)$.

The association between vitamin $\mathrm{K}$ and WM dose observed in our study was only marginal $(\mathrm{p}=0.06)$ and is consistent with findings from a study by Aquilante et al. [15], who reported a weak association $(\mathrm{p}=0.05)$ among 350 patients. The relatively low mean intake of vitamin $\mathrm{K}$ $(127 \pm 129 \mu \mathrm{g} /$ day) in our study compared to others (approx. $250 \mu \mathrm{g} /$ day) [12] could in part explain the weak association that we observed.

Our findings are consistent with those of others in which vitamin $\mathrm{K}$ intake from the diet or on prescription has been associated with higher WM doses [3], though the overall contribution of vitamin $\mathrm{K}$ is generally small. For instance, in a study that examined genetic factors, diet, physical activity and body weight using multivariate data-reduction techniques, genetic factors explained $52 \%$ of the variance in the WM dose, while diet, physical activity and body weight only explained 8\% [4]. Although there was a suggestion for a nonlinear relationship between vitamin K intake and WM dose in univariate analyses, further analyses with vitamin $\mathrm{K}$ as a polynomial term did not reveal evidence for a nonlinear relationship.
Our study had limitations. First, vitamin K assessed from DR is subject to measurement error. Vitamin $\mathrm{K}$ in plasma is not very stable and is thus also subject to measurement error. We averaged multiple DR, an approach which we believe improved our estimate of vitamin $\mathrm{K}$ intake. Secondly, only 172 patients had complete data on major determinants of warfarin response (e.g. VKORC1 and $C Y P 2 C 9$ ). This precluded analyses stratified by more BMI categories so as to better understand the effect of body fat on the relation between vitamin $\mathrm{K}$ and warfarin response.

This study had a number of strengths including availability of data on genetic polymorphisms known to affect warfarin response, e.g. VKORC1, CYP2C9 and CYP4F2. Our analyses adjusted for polymorphisms in these genes and further extended the investigation to the potential contribution of the interaction between BMI and vitamin $\mathrm{K}$ in explaining variance in warfarin response seeing as genetic polymorphisms only partially explain the variance in the response to warfarin [2].

\section{Conclusions}

We found no interaction between BMI and vitamin $\mathrm{K}$ intake with regard to warfarin response. Vitamin K intake was marginally associated with warfarin response and 
adding it to the model with standard predictors such as VKORC1 and CYP2C9 genotypes only slightly increased the variance in warfarin response that was explained by the model (change in $\mathrm{r}^{2}=1.1 \%$ ). This small improvement in variance explained is consistent with the marginal improvement reported for overall diet.

\section{Acknowledgements}

This study was supported by grant R01HL092173 from the National Heart, Lung and Blood Institute, National Institutes of Health.

\section{References}

1 Cho HJ, Sohn KH, Park HM, Lee KH, Choi B, Kim S, Kim JS, On YK, Chun MR, Kim HJ, Kim JW, Lee SY: Factors affecting the interindividual variability of warfarin dose requirement in adult Korean patients. Pharmacogenomics 2007;8:329-337.

2 Phillips KW, Dobesh PP, Haines ST: Considerations in using anticoagulant therapy in special patient populations. Am J Health Syst Pharm 2008;65:S13-S21.

-3 Absher RK, Moore ME, Parker MH: Patientspecific factors predictive of warfarin dosage requirements. Ann Pharmacother 2002;36: 1512-1517.

4 Rasmussen M, Skov J, Bladbjerg E-M, Sidelmann J, Vamosi M, Jespersen J: Multivariate analysis of the relation between diet and warfarin dose. Eur J Clin Pharmacol 2012;68: 321-328.

5 Shea MK, Booth SL, Gundberg CM, Peterson JW, Waddell C, Dawson-Hughes B, Saltzman E: Adulthood obesity is positively associated with adipose tissue concentrations of vitamin $\mathrm{K}$ and inversely associated with circulating indicators of vitamin K status in men and women. J Nutr 2010;140:1029-1034.
-6 Meyer zu Schwabedissen C, Mevissen V, Schmitz F, Woodruff S, Langebartels G, Rau T, Zerres K, Hoffmann R, Ortlepp JR: Obesity is associated with a slower response to initial phenprocoumon therapy whereas CYP2C9 genotypes are not. Eur J Clin Pharmacol 2006; 62:713-720.

7 Morabia A, Ross A, Curtin F, Pichard C, Slosman DO: Relation of BMI to a dual-energy $\mathrm{X}$-ray absorptiometry measure of fatness. Br J Nutr 1999;82:49-55.

$>8$ Limdi NA, Limdi MA, Cavallari L, Anderson AM, Crowley MR, Baird MF, Allon M, Beasley TM: Warfarin dosing in patients with impaired kidney function. Am J Kidney Dis 2010;56:823-831

$>9$ Liang R, Li L, Li C, Gao Y, Liu W, Hu D, Sun Y: Impact of CYP2C9*3, VKORC1-1639, CYP4F2rs2108622 genetic polymorphism and clinical factors on warfarin maintenance dose in Han-Chinese patients. J Thromb Thrombolysis 2012;34:120-125.

10 Nutrition Data System for Research (NDSR). http://wwwnccumnedu/products/ndsrgrantwritershtml (accessed 6 December 2012).
11 Kabagambe EK, Baylin A, Allan DA, Siles X Spiegelman D, Campos H: Application of the method of triads to evaluate the performance of food frequency questionnaires and biomarkers as indicators of long-term dietary intake. Am J Epidemiol 2001;154:1126-1135.

12 Lubetsky A, Dekel-Stern E, Chetrit A, Lubin F, Halkin H: Vitamin K intake and sensitivity to warfarin in patients consuming regular diets. Thromb Haemost 1999;81:396-399.

13 Willett WC: Nutritional Epidemiology, ed 2. New York, Oxford University Press, 1998.

14 Wells PS, Majeed H, Kassem S, Langlois N, Gin B, Clermont J, Taljaard M: A regression model to predict warfarin dose from clinical variables and polymorphisms in CYP2C9, CYP4F2, and VKORC1: derivation in a sample with predominantly a history of venous thromboembolism. Thromb Res 2010; 125:e259-e264.

15 Aquilante CL, Langaee TY, Lopez LM, Yarandi HN, Tromberg JS, Mohuczy D, Gaston KL, Waddell CD, Chirico MJ, Johnson JA: Influence of coagulation factor, vitamin $\mathrm{K}$ epoxide reductase complex subunit 1 , and cytochrome P450 2C9 gene polymorphisms on warfarin dose requirements. Clin Pharmacol Ther 2006;79:291-302. 